\title{
Editorial: Make models work for water science and engineering
}

1 Yuesuo Yang MSc, PhD

Director Environmental Hydrogeology, Cardiff University, Cardiff, UK
2. Yanxin Wang PhD

Professor, MOE Key Laboratory of Biogeology and Environmental Geology and School of Environmental Studies, China University of Geosciences, Wuhan, PR China

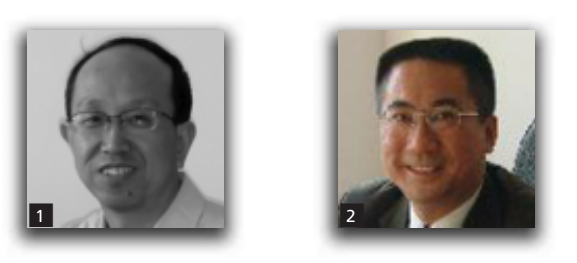

Numerical modelling plays an increasingly important role in water science and engineering. It is also recommended as an effective tool for many aspects in water management. Complex data from geo-hydrological and environmental investigations can be interpreted and described by reasonable models with a direct and vivid presentation of their spatial-temporal variations. Further scenario analysis using numerical models can provide decision support for water management (e.g. contamination control and remediation, strategies of water supply). Over the past few decades, groundwater modelling has transferred its character of social demands from traditional standalone studies toward more comprehensive functioning for holistic water resources management. Numerical models for atmospheric, surface water and groundwater processes can be coupled to present the integrated water system, sometimes with statistic, stochastic and operating models for reducing uncertainty and optimising strategies. However, model calibration becomes a key focus to show how we can effectively make these models work in real applications of water science and engineering.

The 7th International Conference on Calibration and Reliability in Groundwater Modelling (ModelCARE2009) was hosted by the International Association of Hydrological Sciences (IAHS) to promote academic exchanges in this field. The papers in this themed issue of Water Management are selected from the presentations at this conference. These papers highlight the applicability of various models to real-world problems in different cases and show future potential needs and directions toward progress in water research and development.

Karst groundwater has always been a challenging issue as karstified aquifers have complex and distinct characteristics that make them very different from other types of aquifers. Ample supply, heterogeneous structure and vulnerability to pollution make it significant to study karst groundwater for sustainable development of human society. The paper by Gao et al. (2011) introduces a statistical model to assess the anthropogenic impacts on Niangziguan karst water in northern China. This model combines box and whisker plot and factor and cluster analyses of the hydrochemical data. The results show significant geographic variation of chemical constituents throughout the karst groundwater system which relates to human activity. Factor analysis indicates abnormally high levels of some components are caused by agriculture, mining wastewaters and sewage discharge. The evolution of groundwater chemistry in regional groundwater systems was identified by cluster analysis modelling to be under the joint control of natural and anthropogenic processes.

Groundwater over-exploitation has induced depression cones all over the world. Groundwater artificial recharge (GAR) is considered a promising method for dealing with these problems. Water imported from rivers and other sources is recharged into aquifers and physical, chemical and water-rock reactions take place in the recharge water, native groundwater and aquifer matrix during this process. However, changes in water quality after GAR by clean water have not been addressed for a long time. Ye and Du (2011) attempt to explore the complex hydro-geochemical process during GAR using groundwater geochemistry modelling to forecast the interaction between recharge water, native groundwater and aquifer matrix. The new approach was applied in the Daqing groundwater depression cone in north-east China. The modelling results show a tendency of water quality change in aquifer, which is helpful to identify health risks and assess the feasibility of artificial recharge in this region.

Land subsidence is another problem induced by groundwater over-exploitation. Simulation of regional land subsidence involves a groundwater flow model and a subsidence model. Previous integrated models have been difficult to apply to practical problems due to too many parameters required. In this paper, Ye et al. (2011a) develop a regional land subsidence model to describe the visco-elastic-plastic deformation based on the modified Merchant model by setting proper values of the parameters involved. A new numerical method, the multi-scale finite-element method (MsFEM) was also proposed to model the regional land subsidence problems. Application of this model in Shanghai 
showed a good calibration between the modelled results and observed data, as well as the great capability in describing land subsidence with complicated deformation characteristics. MsFEM was demonstrated as a good numerical method that significantly reduces computing effort for accurate results.

Ambient temperatures can influence water movement and heat transport underground, which is a practical and prominent issue in most arid and semi-arid areas. Wang et al. (2011) contribute to the progress on numerical modelling of water movement in the vadose zone influenced by temperature from four aspects: the mechanisms and effective factors in the movement of water and heat in the vadose zone under surface evaporation conditions; the mechanisms of phreatic water evaporation at different groundwater levels under evaporation conditions; phreatic water evaporation intensity and limited depth of evaporation of groundwater driven by surface temperature; and the differences between an isothermal model and a coupled water and heat model when used to analyse water movement in the vadose zone.

With deterioration due to environmental pollution, the diagnosis and forecasting of the health status of groundwater environments at a regional scale is in big demand. A new concept for groundwater environment health is introduced by Ye et al. (2011b) to diagnosis the health status of a groundwater environment by an assessment index system. Six basic categories (survival, effectiveness, freedom, security, adaptation and coexistence) in this index system represent various aspects of the health status of a groundwater environment. A projection pursuit (PP) model was developed for the assessment of groundwater environments and PP grade evaluation (PPGE) was used to evaluate the health status of a groundwater environment. The authors apply this model in the paper as a tool for groundwater environment management in Western Jilin province, China. Results from this model can be used by decision makers and could also be published to raise awareness of understanding of the environmental situation among local people.

Hydrogeochemical simulation is a hard task in groundwater modelling not only due to the complex processes involved but also difficulty in calibrations. Guo et al. (2011) present a multi- isotope approach to calibrate the inverse geochemical modelling in Xinzhou basin, northern China. Results from the inverse geochemical modelling indicate that geochemical evolution of the groundwater was dominated by dissolution and precipitation, and further information supplemented by the isotope data indicates that mixing and evaporation processes also occurred. Therefore, this study provides an example for the calculation of hydrogeochemical modelling. The multi-isotope/tracer approach can provide an effective method to reduce the uncertainty of the conceptual model to make the model more reliable, and will help to identify the major processes controlling hydrogeochemistry of groundwater on a regional scale.

\section{REFERENCES}

Gao X, Wang Y, Ma T et al. (2011) Anthropogenic impact assessment of Niangziguan karst water. Proceedings of the Institution of Civil Engineers, Water Management 164(10): 495-510, http://dx.doi.org/10.1680/wama.1000070.

Guo X, Gan Y and Wang Y (2011) Calibration of hydrogeochemical model by multi-isotope approach. Proceedings of the Institution of Civil Engineers, Water Management 164(10): 559-567, http://dx.doi.org/10.1680/ wama.1000066.

Wang W, Zhao G, Li J et al. (2011) Experimental and numerical study of coupled flow and heat transport. Proceedings of the Institution of Civil Engineers, Water Management 164(10): 533-547, http://dx.doi.org/10.1680/wama.10.00088.

Ye $X$ and Du X (2011) Impact of artificial recharge on water quality in groundwater depression cone. Proceedings of the Institution of Civil Engineers, Water Management 164(10): 511-517, http://dx.doi.org/10.1680/wama.10.00063.

Ye S, Xue Y, Wu J et al. (2011a) Regional land subsidence model embodying complex deformation. Proceedings of the Institution of Civil Engineers, Water Management 164(10): 519-531, http://dx.doi.org/10.1680/wama.1000062.

Ye XY, Wang KJ, Du XQ and Cao JF (2011b) Health diagnosis of groundwater environment based on a projection pursuit model. Proceedings of the Institution of Civil Engineers, Water Management 164(10): 549-557, http://dx.doi.org/ 10.1680/wama.2011.164.10.549. 